\title{
Reflections on Phenomenology, Pedagogy, and \\ Phenomenology + Pedagogy
}

\author{
David W. Jardine \\ University of Calgary
}

The light dove, cleaving the air in her free flight, and feeling its resistance, might imagine that its flight would be still easier in empty space. (Immanuel Kant, Introduction to the Critique of Pure Reason, 1964)

This passage captures for me a vague uneasiness that I have felt regarding the image of phenomenology that has occasionally been presented in Phenomenology + Pedagogy over the past few years. The latest issue has just arrived, and I perused it with as much enjoyment as ever. But the uneasiness persists. This open letter is meant to give a voice to that uneasiness. It is not intended as an attempt to turn away from Phenomenology + Pedagogy and what it has to offer. Rather, it is an attempt to understand what it has to offer by understanding my own uneasiness with it.

My experience with phenomenology began with Edmund Husserl and the seemingly liberating effects of the phenomenological turn from objectivistic, methodological inquiry to a reflective inquiry into everyday life, into the complex and rich contours of our lived experience of the world. But what has always enamored me in this turn are passages like the following from Husserl's Crisis of European Science (1970):

If we cease being immersed in our scientific thinking, we become aware that we scientists are, after all, human beings and as such are among the components of the life-world which always exists for us, ever pregiven; and thus all of science is pulled, along with us, into the ... life-world. (pp. 130-131)

With this epoche ... neither the sciences nor the scientists have disappeared for us who practice this epoche. They continue to be what they were before, in any case: facts in the unified context of the pregiven life-world. (p. 136)

We [see] that the propositions, the theories, the whole edifice of doctrine in the objective sciences ... have the character of validities for the life-world, adding themselves to its own composition and belonging to it. (p. 131)

Phenomenology + Pedagogy Volume 6 Number 31988 
I take these passages to mean that we already live in a world in which scientific discourse exists, in which it already has a place, a pervasiveness, a commonplaceness. When we turn our attention from pursuing objective scientific work to a reflective interpretation of everyday life, of lived experience, the sciences do not thereby disappear. The scientific theories, the curriculum guides, the images from child development, the administrative and bureaucratic forms of accountability are there as features of lived experience, not as blocks to lived experience that we must somehow sidestep to get to the things themselves (and all the precious yet precocious notions of the pedagogical moment). We cannot attempt to siphon off the pedagogical moment as some pure lived experience, as if we can remain divorced from the full force of the living but deadly presence of other forms of discourse in our lives. A colleague once said to me that we owe nothing to such discourse, and as phenomenologists our task is not to dwell in indebtedness to such discourse but to attend to the matters themselves. To this I say, Yes, and hooray. But I also ask, what is the language of such an unindebted voice? What word(s) shall we use? What shall we say that expresses no indebtedness but just the matters themselves? The moment we move beyond hallucinogenic images of the pedagogical moment, our language interweaves with history, with culture, and with forms of speech other than those we find most precious. Our language already resonates with a whole history of the understanding of being human, and our experience is enformed by such a history (as is our understanding of experience, being enformed, and history). We already find ourselves intractably caught up in everyday life in which the residues of scientific theorizing have already become a validity for the life world.

This everyday way in which things have been interpreted is one into which Dasein has grown in the first instance, with never a possibility of extraction. In it, out of it, and against it, all genuine understanding, interpreting and communicating, all re-discovering and appropriating anew, are performed. In no case is Dasein, untouched and unseduced by this way in which things have been interpreted, set before the open country of a "world-in-itself" so that it just beholds what it encounters. (Heidegger, 1962, p. 213)

The difficulty I have with Phenomenology + Pedagogy is that I cannot just turn away from the appearance of objectivistic, militaristic, economic, epistemological, metaphysical, and bureaucractic forms of speech and retreat into those forms of inquiry which I favor, as if such a retreat leaves me untouched. In living with my son, those forms of speech which refuse what 
phenomenology accepts howl relentlessly. We must not turn away from the struggle to recover the pedagogical moment in, out of, or against the actual conditions of our lives, conditions which are not identical with phenomenological formulations of pedagogy. It is only to the extent that we replace phenomenology in the full living context of everyday life, a context which contains precisely nonphenomenological formulations of children, education, teaching, and so forth, that we will be able to address those who actually find themselves in classrooms. In reaching out to understand the lived character of pedagogy, we experience, as a feature of that lived character, the call for behavioral objectives, administrative accountability, and the mandatory tests given at the end of grades $3,6,9$, and 12 in Alberta. Seeing phenomenology as the opportunity to purge discourse of such residues, such indebtedness, turns it into nothing other than a vague romanticism which turns its back on the pedagogical moment by turning that moment into an idealistic ghost. We cannot happily ignore the fact of living our lives in the face of what we might not want life to be.

I find this whole issue a painful one. I cannot abide the sadsack forms of critical theory which attempt to detail the dismalness and oppressiveness of life. But it is equally painful to see phenomenology become the repository for the romantic and the nostalgic. In the end, we all have different tasks. This is not intended as a form of limp liberalism but as a recognition that we all live different lives. And I realize, in rereading this, that I am in a vague way reliving the life of my teacher in a way analogous to that of my colleague, who, in some way and to some extent, relives the life of his teacher in saying that we owe nothing. And most peculiarly, our recent arguments about Phenomenology + Pedagogy are a reliving of the arguments our teachers have had and, I suspect, will continue to have. So in the end, this letter is not an attempt to behold phenomenology in itself but is the beginning of a struggle in, out of, or against what I have grown into. I suppose, then, to the extent that Phenomenology + Pedagogy has educed this, this letter is the occasion for praise rather than rebuke. Being educed is almost always an occasion for a vague uneasiness. So be it.

\section{References}

Heidegger, M. (1962). Being and time. New York: Harper \& Row. Husserl, E. (1970). Crisis of European science. Evanston, IL:

Northwestern University Press.

Kant, I. (1964). Critique of pure reason. London: Macmillan. 